\title{
MULTI-LACUNAR STROKES MIMICKING ATYPICAL PARKINSONISM WITH AN UNUSUAL NEUROIMAGING PRESENTATION: "ÉTAT CRIBLÉ"
}

\author{
José Luiz Pedroso, Clecio Godeiro-Junior, Andre Carvalho Felício, Antonio Carlos Martins Maia Jr, \\ Camila Catherine H. Aquino, Larissa Teles de Souza, Orlando Graziani Povoas Barsottini
}

Cerebrovascular diseases may present as parkinsonism. Meantime, its clinical and pathological aspects are still imprecise ${ }^{1,2}$. The diagnosis of vascular parkinsonism (VP) is difficult, concerning that basal ganglia infarcts occur in old people and hardly ever parkinsonism is developed ${ }^{3-11}$.

We report a case of atypical parkinsonism whose etiology is vascular, with an uncommon presentation in the images of the brain.

\section{CASE}

A 74-year-old white man presented a 4-month history of progressive gait disorder, rigidity and apathy. His steps were short and falls became frequent due to postural instability. Their relatives related changes in his behavior characterized by visuospatial disorientations and hallucinations. He also had loss of memory for both recent and long-term events. He could not control his urethral and anal sphincters.

The patient had no history of drug abuse (neuroleptic or calcium channel blockers), diabetes mellitus or other metabolic disease (liver or thyroid), except for arterial hypertension. He had no past history of toxin exposure or central nervous system infection. Severe head trauma was not reported, until three weeks before our evaluation, when he had a fall and moderate cranial trauma. The family history was unremarkable.

On neurological exam the patient was conscious, but could not interact with the physician. We could not test his cognitive functions. There was markedly hypomimia and supranuclear vertical and horizontal gaze palsy were found. Myerson sign was present as well as bilateral grasping and groping reflexes. $\mathrm{He}$ presented global severe plastic hypertonia and akinesia. He was completely restricted to bed.

Computed tomography disclosed hypodense lesions in basal ganglia in both sides and a small subdural hematoma. Subdural hematoma was treated, but he presented no clinical improvement. Magnetic resonance disclosed hypointense lesions in both putamen, caudate and thalami (Figure).
He was treated with levodopa, but we did not observe any change in his condition. He died some days later from pneumonia and sepsis.

\section{DISCUSSION}

Differential diagnosis of parkinsonian syndromes encloses idiopathic Parkinson's disease, other primary neurodegenerative diseases (multiple system atrophy, progressive supranuclear palsy, corticobasal degeneration and
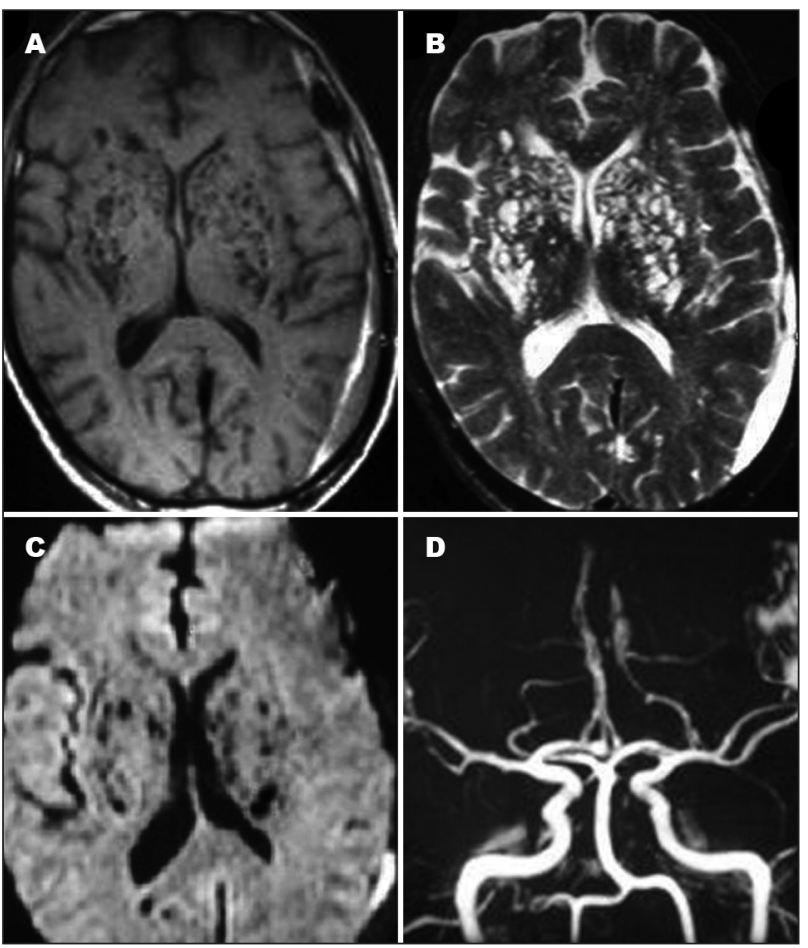

Figure. Lacunar state. T7 (A), T2 (B) and DWI (C) axial image shows multiple bilateral and confluent hypointense lesions in both putamen, caudate, and thalami - État Criblé. There are no signs of acute infarct on DWI (C) or major arterial stenosis on MRA (D). Note a small left chronic subdural hematoma ( $A$ and $B$ ). 
Table. Differential diagnosis of parkinsonian syndromes.

Idiopathic Parkinson's disease

Monogenetically inherited forms of Parkinson's disease

Symptomatic parkinsonism

- Drug-induced

- Toxic

- Inflammatory

Pseudoparkinsonism

- Vascular

- Normal pressure hydrocephalus

Atypical parkinsonism

- Multiple system atrophy (MSA-P, MSA-C)

- Progressive supranuclear palsy, Steele-Richardson-Olszewski syndrome (PSP)

- Corticobasal degeneration (CBD)

- Dementia with Lewy bodies (DLB)

dementia with Lewy bodies), symptomatic parkinsonism and pseudoparkinsonism, like vascular parkinsonism and normal pressure hydrocephalus ${ }^{12}$.

A number of case reports have highlighted the occurrence of parkinsonism following strategic infarcts affecting the basal ganglia but the prevalence of parkinsonism after striatal infarcts has not been assessed'.

Atypical parkinsonism, including dementia and gait disorders is one of a growing number of recognized ways that multi-infarcts strokes may present. Recent studies have demonstrated that VP correspond around 2,5 to $3 \%$ of all cases presented with parkinsonism².

Although VP occurs frequently in the elderly, its clinical features have not been investigated in detail, particularly in comparison with Parkinson's disease (PD) $)^{5,6}$. Some semiological aspects are of particular interest when we consider the differences between VP and PD: the prevalence of pathological reflexes, was significantly higher in the VP patients than in the PD patients. In special, snout reflex and palmomental reflex were more frequent in the VP patients ${ }^{5}$.

Winikates and Jankovic described 69 cases of VP, including its clinical correlates. Patients with VP were older, more likely to present with gait difficulty rather than tremor, and less likely to respond to the use of levodopa compared with patients with PD. Patients with VP were also significantly more likely to have postural instability, a history of falling, dementia, corticospinal findings, incontinence and pseudobulbar effects. These differences in clinical features suggest a different pathogenesis of parkinsonism in these two patients groups ${ }^{7}$. Moreover, we must bear in mind that VP is underdiagnosed. The typical characteristics of bilateral and symmetrical onset, rigidity and bradykinesia, absence response to levodopa and altered neuroimaging exams compatible with vascular lesions must suggest the diagnosis of $\mathrm{VP}^{8}$.

In the present case, we highlight an unusual neuroimaging presentation of vascular parkinsonism named état criblé. The term état criblé (cribriform state) was described in 1842 and it refers to the dilatation of perivascular spaces around cerebral arterioles in the brain of elderly people and the radiological images based on magnetic resonance discloses hypointense lesions in both putamen, caudate and thalami on T1-weighted and hyperintense lesions on T2-weighted. There few cases of vascular parkinsonism presenting as état criblée.

Two types of cribriform cavities have been identified, according to the histological appearance of the surrounding tissue: type 1 with normal gliotic surrounding nervous tissue, and type 2, with rarefied and abnormally gliotic surrounding nervous tissue. Mancardi and coworkers identified sixteen patients that exhibited a pseudobulbar palsy or extrapyramidal rigidity between thirty patients with cribriform state in the basal ganglia ${ }^{5}$.

A likely explanation would be that such infarcts will only exceptionally selectively disrupt putamino-pallidal outflow but will normally also involve pallidal damage ("pallidotomy effect") and putaminal infarcts themselves will not differentially affect the direct and indirect pathways as in dopamine deficiency ${ }^{1,10-12}$.

The pathology of these cases showed macroscopically visible lacunar infarcts or lacunae caused by enlarged perivascular space in or near nigrostriatal pathway, but no small vessel disease affecting the thalamocortical drive?

\section{REFERENCES}

1. Peralta C, Werner P, Holl B, et al. Parkinsonism following striatal infarcts: incidence in a prospective stroke unit cohort. J Neural Transm 2004;111:1473-1483.

2. Fujimoto K. Vacular parkinsonism. J Neurol 2006;253:16-21.

3. Rektor I, Rektorová I, Kubová D. Vascular parkinsonism: an update. J Neurol Sci 2006;248:185-191.

4. Okuda B, Kawabata K, Tachibana H, Kamogawa K, Okamoto K. Primitive reflexes distinguish vascular parkinsonism from Parkinson's disease. Clin Neurol Neurosurg 2008;110:562-565.

5. Mancardi G L, Romangnoli P, Tassinari T, Gandolfo C, Primavera A, Loeb C. Lacunae and cribriform cavities of the brain: correlations with pseudobulbar palsy and parkinsonism. Eur Neurol 1988;28:11-17.

6. Winikates J, Jankovic J. Clinical correlatos of vascular parkinsonism. Arch Neurol 1999;56:98-102.

7. Silva EG, Viana MA, Quagliato EMAB. Vascular parkinsonism: analysis of seven cases. Arq Neuropsiquiatr 2006;64:568-571.

8. Zijlmans JCM, Daniel SE, Hughes AJ, Révész T, Lees AJ. Clinicopathological investigation of vascular parkinsonism, including clinical criteria for diagnosis. Mov Disord 2004;19:630-640.

9. Demirkiran M, Bozdemir H, Sarica Y. Vascular parkinsonism: a distinct, heterogeneous clinical entity. Acta Neurol Scand 2001;104:63-67.

10. Murrow R W, Schweiger G D, Kepes J J, Koller W C. Parkinsonism due to basal lacunar state: a clinicopathological correlation. Neurology 1990;40:897-900.

11. Román GC. On the history of lacunes, état criblé, and the white matter lesions of vascular dementia. Cerebrovasc Dis 2002;13:1-6.

12. Lachenmayer L. Differencial diagnosis of parkinsonian syndromes: dynamics of time courses are essential. J Neurol 250;1:11-14. 